Median age of FLD diagnosis was 35 (IQR 25-43, range 16-62), with a median latent period from first farm exposure of 28 years (IQR 20-42).

Discussion The prevalence of FLD in this British cohort (representing over $1 \%$ of British farmers) was in keeping with that reported from other countries. Age of diagnosis was very variable, with the majority of those affected having never smoked. Although most had worked on a mixture of farm types, workers with FLD were more likely to report only having lived on an animal versus cereal production farm

\section{EXPOSURE TO CRYSTALLINE SILICA AND LUNG FUNCTION IN OUTDOOR ROCK DRILLERS}

Bente Ulvestad, Nils Petter Skaugset, Berit Bakke, Kari Dahl, Dag Gunnar Ellingsen. National Institute Of Occupational Health, Oslo, Norway

\subsection{6/oemed-2018-ICOHabstracts.1259}

Introduction A number of tasks in heavy construction generate crystalline silica dust, which is a significant contributor to occupational mortality and morbidity. When a new heavy construction site is established, first excavators come to clear the soil. Thereafter holes are drilled to prepare for blasting. There is a lack of knowledge regarding exposure levels of dust and crystalline silica among rock drillers and blasting workers generated by these work tasks. Exposure to dust and crystalline silica are suggested to cause obstructive and restrictive lung changes.

Methods The study is designed as a two years follow-up of 132 rock drillers and 50 referents (administrative personnel) working in the same construction companies, but without airborne occupational exposure. All subjects were examined with lung function tests and blood was collected during the winter $2015 / 2016$. They will be re-examined in 2017/2018. Pneumoproteins and markers of inflammation are currently being analysed.

Eighty-three rock drillers using different drilling rigs carried air-sampling equipment for the determination of respirable dust and crystalline silica.

Result Preliminary results show: The exposure to dust and crystalline silica in the respirable aerosol fraction ranged from 0.01 to $2.91 \mathrm{mg} / \mathrm{m}^{3}$, and from 0.002 to $0.45 \mathrm{mg} / \mathrm{m}^{3}$, respectively, depending on type of drilling equipment in use. Workers using drill rigs with feed mounted operation panels were most highly exposed.

Compared with the referents at baseline the rock drillers had significantly lower forced vital capacity (FVC)\% predicted $(\mathrm{p}=0.012)$ and forced expiratory volume in one second $\left(\mathrm{FEV}_{1}\right) \%$ predicted $(\mathrm{p}=0.001)$. The decline in $\mathrm{FEV}_{1} / \mathrm{FVC}$ (Tiffeneau index) was associated with years of exposure $(p=0.017)$ and smoking (pack years) $(p=0.02)$. The serum concentration of CRP was comparable between the two groups.

Discussion Exposure to crystalline silica during rock drilling may have negative impact on the lung function.

\section{CHEST CT SCANNING IN THE SCREENING, SURVEILLANCE, AND DIAGNOSIS OF OCCUPATIONAL LUNG DISEASES}

Rafael E de la Hoz. Icahn School of Medicine at Mount Sinai, New York, NY, USA
Aim of special session Advances with chest CT scanning and CT scan-based lung cancer screening are changing the way diagnosis and screening for occupational lung diseases are conducted. We plan to review existing methodologies and experience-based emerging strategies.

Thomas Kraus, MD, $\mathrm{PhD}^{1}$, Kurt G. Hering, $\mathrm{MD}^{2}$, Narufumi Suganuma, $\mathrm{MD}, \mathrm{PhD}^{3}$, and Rafael E. de la Hoz, MD, $\mathrm{MPH}, \mathrm{MSc}^{4}$

${ }^{1}$ RWTH Aachen, Aachen, Germany

${ }^{2}$ Knappschafstkrankenhaus Dortmund, Dortmund, Germany

${ }^{3}$ Kochi Medical School, Kochi University, Nankoku 7838505, Japan

${ }^{4}$ Icahn School of Medicine at Mount Sinai, New York, NY, USA

\begin{tabular}{|l}
\hline $1677 a$ \\
INTERNATIONAL CLASSIFICATION OF HRCT FOR \\
OCCUPATIONAL AND ENVIRONMENTAL RESPIRATORY \\
DISEASES: DESCRIBING NON-MALIGNANT AND \\
MALIGNANT ASBESTOS RELATED DISEASES
\end{tabular}

Narufumi Suganuma. Kochi Medical School, Kochi University, Nankoku, Japan

10.1136/oemed-2018-ICOHabstracts. 1261

ILO Classification of Radiograph of Pneumoconioses (ILO/ICRP) has played an important role in screening and surveillance of pneumoconiosis among dust exposed workers worldwide. As the ILO/ICRP has semi-quantitative scheme, it allows objective and standardised recording of radiographic findings on chest radiographs of workers. The International Classification of HRCT for Occupational and Environmental Respiratory Diseases (ICOERD) have been proposed from International Expert Team consists of researchers from 7 countries, based on the consensus report at the Helsinki Meeting for Asbestos related diseases in 2000. The ICOERD system covers all aspect of Occupational and Environmental Respiratory Diseases, starting with six parenchymal findings and two pleural abnormalities. Parenchymal findings include well-defined rounded opacities, irregular opacities, inhomogeneous attenuation, honeycombing, emphysema and large opacities. Irregular opacities include intralobular opacities and interlobular opacities, the former include centrilobular opacities suggestive of inhalation diseases. The ICOERD classifies these parenchymal findings in 4-point-scale, grading 6 lungs zones. Consequently, the final grade for each of the parenchymal findings sums up to 18point-scale. Pleural abnormalities cover pleural thickening of parietal and/or visceral types. Width and extent of pleural thickening is graded in 4-point-scale. As multi-detector CT can be used for screening of non-malignant and malignant diseases, the ICOERD added supplemental coding for mesothelioma, which allows standardised recording of findings suggestive of mesothelioma. CT findings of unilateral pleural effusion, nodular pleural thickening, mediastinal pleural thickening, interlobar fissure thickening, diminished lung, contracted hemithorax should be noticed when reviewing CT scans of asbestos-exposed persons.

\section{$1677 \mathrm{~b}$ EXPERIENCE WITH THE ICOERD CLASSIFICATION IN WTC LUNG DISEASES}

Rafael E de la Hoz. Icahn School of Medicine at Mount Sinai, New York, NY, USA

10.1136/oemed-2018-ICOHabstracts. 1262 
The terrorist attack on 9/11/2001, and subsequent rescue, recovery, and service restoration of the World Trade Centre disaster site in New York City, created an unprecedented and unique occupational and environmental exposure that affected a large and diverse group of rescue workers and volunteers. The workers were exposed to a mixture of poorly characterised inhaled toxicants. A variety of acute and chronic respiratory illnesses have been reported among all exposed workers, which are the subject of large scale ongoing investigation and follow up. Our group created the WTC Chest Imaging Archive as a repository for more than 3500 chest CT scan studies in about 1700 WTC workers. We systematically assessed imaging abnormalities by means of the International CT Classification of Occupational and Environmental Respiratory Diseases. An examination of the first available chest CT scan for each subject $(n=1453)$ with complete available data, a median of 6.8 years after September 11, 2001 revealed that the most frequent recorded abnormalities were pleural abnormalities (parietal in $7.9 \%$ of the workers, and visceral in $12.8 \%$ of them), inhomogeneous attenuation (13.2\%), irregular/linear opacities (12.9\%), and emphysema (12.0\%). With regards to pleural abnormalities, although we found them across all 5 broad occupational groups, they were more frequent among construction labourers/asbestos handlers/building cleaners, most of whom were first-generation immigrants. Many of those abnormalities were not reported by clinical radiological readings. Visceral, but not parietal pleural changes were associated with mild pulmonary function impairment. Future studies will examine the evolution of imaging abnormalities, and add computerised quantitative CT scan to their assessment.

\section{C GERMAN EXPERIENCE USING ILO AND ICOERD-CODING IN THE SURVEILLANCE OF ASBESTOS- AND QUARTZ- EXPOSED WORKERS}

${ }^{1}$ Thomas Kraus, ${ }^{2}$ Kurt G Hering. ${ }^{1}$ RWTH Aachen, Aachen, ${ }^{2}$ Knappschafstkrankenhaus Dortmund, Dortmund, Germany

10.1136/oemed-2018-ICOHabstracts.1263

Currently, there are about 60 to 70000 individuals on the surveillance program per year out of $>500000$ registered asbestos exposed persons, 240000 of them get an offer for medical examination, lung function and a chest X-ray every 3 years. Ca. $90 \%$ of the data (results of examination, lung function and conventional ILO-coding sheet) are transferred online.

Approximately $10 \%$ of the examined candidates gets a Low Dose Volume-HRCT. Lung cancer screening examinations in a high risk group have been started. Depending on the knowledge using the ILO International Classification of Radiographs of Pneumoconioses as universal standard for screening and health surveillance of individuals occupationally exposed to dusts, a standardised coding system has been demanded as obligatory not only for epidemiological purposes, but also as diagnostic criteria for occupational diseases.

The ILO classification is a standard surveillance tool, in use for more than 50 years in Germany. In 2005, a monograph 'International Classification of HRCT for Occupational and Environmental Respiratory Diseases - ICOERD' has been published. The work represented a consensus of international experts from Belgium, Finland, France, Germany, Great Britain, Japan and United States on a principal coding system along with reference films and imaging parameters. The reference films include examples with 5 and $1 \mathrm{~mm}$ slice thickness (incremental CT) for typical pleural and parenchymal findings.

Experienced radiologists will make the classification, or a CD-ROM with subjects' images will be sent to a B-Reader for classification. For coding purposes the reference-films are part of the classification. The reading results will be stored online at the Online-Portal-GVS-Server, which is provided by GVS Health Prophylaxis - a joint facility of the German Statutory Accident Insurance.

ILO-criteria for diagnosing asbestos related diseases are as follows: s, t, u irregular densities, more or equal 1/1 without and $1 / 0$ with inspiratory crackles or impairment of vital capacity, pleural thickening (plaque also unilateral at least $3 \mathrm{~mm}$ thickness, length $2 \mathrm{~cm}$, diffuse pleural thickening $2 \mathrm{a}$ both middle and lower field). ICOERD criteria for diagnosing asbestos related diseases are as follows: irregular and/or linear opacities in both lower and/or middle fields, sum profusion of at least 4 , any visible pleural thickening, visceral or pleural at least $1 \mathrm{a}$, with or without calcification, after exclusion of other causes. Similar criteria for silicosis will be presented.

\section{Conclusion}

- Taking into account the German experience with the coding system as part of guidelines for coding asbestosis, asbestosrelated pleural findings, silicosis and other occupational lung diseases, the HRCT-reference films are part of the standardised classification system (ICOERD).

- The documentation of reading and general surveillance data of dust exposed workers at a Online-Server meets the demand for displaying, reading and classifying subject data. Our German experiences with using the ILO and ICOERDclassification will be presented.

- HRCT-findings of occupational respiratory lung diseases should be classified using a standardised coding and scoring system. Reference films are provided to harmonise the description and documentation to achieve a reproducible score of the disease.

\section{ASSESSMENT OF JOB-RELATED ASTHMA CASES: OUR THREE-YEAR EXPERIENCE}

Ayşe Coşkun Beyan, Nur Şafak Alıcı, Arif Çımrın. Dokuz Eylul University Occupational Medicine Department, Izmir, Turkey

\subsection{6/oemed-2018-ICOHabstracts. 1264}

Introduction Work-related asthma (WRA) is one of the most common occupational diseases. There is no reliable statistical data for WRA in Turkey. In this study, we aimed to review diagnosing procedures and the characteristics of patients who were diagnosed with WRA at our clinic.

Methods Global Initiative for Asthma guideline was used to establish the diagnosis of asthma. Spirometric measurement, reversibility test and BPT were performed according to ATS criteria.Detailed occupational history was gained with questioning the job(s) starting from the first job, used material(s), duration, time, place properties chronologically and extensively. The relation of the complaints with job was defined. PEF measurements were performed for at least four times, for at least two weeks in working environment and at least two weeks during resting period. A graphic was createdusing the Microsoft Office Excel program taking the highest measurement of daily four sessions into account separately for resting 